\title{
An Approach to Industrial Real Estate Market Segmentation and Valuation Using the Arbitrage Pricing Paradigm
}

\author{
Terry V. Grissom, Texas A\&M University \\ David Hartzell, University of Texas at Austin \\ Crocker H. Liu, University of Texas at Austin
}

This paper investigates whether a segmented market exists for industrial real estate with respect to risk and return characteristics. Given the existence of industrial market segmentation, the next issue examined is whether a submarket perspective or an integrated real estate market orientation provides better rate of return estimates for individual industrial properties using an Arbitrage Pricing Theory (APT) framework. The results support the existence of regional markets for industrial real estate. A submarket orientation rather than an integrated perspective is also found more appropriate in predicting returns on industrial real estate.

\section{Introduction}

A common perception exists among academics and practitioners that the real estate market is actually a series of localized submarkets. Each micromarket is presumed to provide the major systematic influence on value for all properties trading within that particular submarket environment. Empirical evidence generally supports this segmented market hypothesis. Controversy exists however as to whether this submarket perspective results in more efficient value estimates relative to estimates generated under an integrated market assumption. Most of these real estate studies have addressed market segmentation and valuation relative to a given segment using a housing market orientation. A segmented market is deemed to occur in these studies if the value of an attribute(s) varies for identical properties located in different neighborhoods. Physical, legal, and environmental attributes are used in comparing properties across subareas. No real estate literature on the other hand investigates the possibility of industrial real estate submarkets nor the appropriate valuation orientation to employ. Literature is also nonexistent as to whether real estate is segmented in terms of risk and return characteristics. The purpose of this study therefore is to investigate whether a segmented market exists 
for industrial real estate with respect to risk and return characteristics. Given the existence of industrial real estate submarkets, the next issue examined is whether a submarket perspective or an integrated real estate market orientation provides better rate of return estimates for individual industrial properties using an Arbitrage Pricing Theory (APT) framework.

For purposes of this paper, a segmented industrial real estate market is deemed to exist if all of the following conditions are satisfied:

i. The risk premium(s) associated with a common systematic risk attribute(s) differs for industrial properties located in different regions,

ii. The number of risk attributes that are priced differs across regions, and

iii. The return on industrial properties in different regions are associated with different risk factors. Some risk factors are systematic across regions while other risk factors are unsystematic (systematic only within a given region). Further, some of the unique risk factors for a given region are priced while the systematic risk factors are not compensated for in all regions.

This definition of market segmentation differs from the traditional land economic definition since the latter assumes that the valuation model used in determining whether market segmentation exists is portable across all neighborhoods. Portability means that the same attributes are priced in each submarket and that buyers do not compensate sellers for any other attribute(s). Conditions ii) and iii) in contrast recognize that different risk attributes might influence property return in various submarkets even if the same pricing paradigm holds. ${ }^{1}$

This report proceeds in the following manner. The second section provides a brief literature review of market segmentation and valuation. The data used in this study is discussed in the third section. Section four details the methodology employed while the test results of market segmentation coupled with the related valuation issues are found in section five. Conclusions and policy recommendations are presented in the final section.

\section{Brief Literature Review}

Most real estate studies use a housing market orientation together with a hedonic pricing model (HPM) framework to address whether a segmented market exists and to evaluate the appropriateness

\footnotetext{
${ }^{1}$ The Dale-Johnson [1982] definition of market segmentation represents one of the few departures from the traditional land economic definition. Using Q-factor analysis, Dale-Johnson found that diverse factors influence the formation of market segments.
} 
of property valuation with respect to a given segment. The HPM relates the price of a property as a function of its physical, legal, and environmental characteristics. Mathematically, the HPM is of the form

(1)

$P(\underline{x})=\underline{p} \cdot \underline{x} \underline{x} \in R^{m}$

where $P(x)$ is the market price of a type of real estate, $\underline{x}$ is a vector consisting of $\mathrm{m}$ property attributes, $\underline{p}$ is a vector of $\mathrm{m}$ implicit hedonic prices, and $\bullet$ is the inner product or dot product. Evidence for a segmented housing market is deemed to exist if the hedonic prices for identical properties vary across neighborhoods or some other geographical unit of observation.

Empirical studies generally concur that housing submarkets exist. The Bajic [1985], Goodman [1981], Dale-Johnson [1982], Richardson and Thalheimer [1982], Straszheim [1974], Schnare and Struyk [1976], and Sonstalie and Portney [1980] studies all find evidence to support the housing market segmentation hypothesis. All of these studies implicitly presume that the HPM is portable across submarkets. Consequently, the same attributes are priced in each neighborhood. The only exception to this prespecification of market segments is the Dale- Johnson study [1982]. Using Q-factor analysis, Dale-Johnson found that diverse factors influence the formation of market segments. Controversy exists however as to whether more precise property value estimates arise through focusing solely on the micromarket environment within which a property trades. Richardson and Thalheimer [1982], Schnare and Struyk [1976], and Sonstalie and Portney [1980] all found that estimating separate pricing equations for each submarket does not increase the predictive power of intra-SMSA variations in the price of housing. In contrast to this, the studies of Goodman [1981] and Dale-Johnson [1982] found evidence that market segmentation improves the predictability of market values.

Hoag [1980] has recently proposed a new multifactor valuation model for income-producing real estate that captures the "spirit" of the HPM. The model is used to construct value indices for nonowner occupied industrial property. Following is a mathematical representation of the Hoag model:

(2)

$$
P_{i t}=\alpha_{0}+\underline{\alpha}_{f} f+\underline{\alpha}_{n} n+\underline{\alpha}_{l} l+\underline{\alpha}_{q} q+\epsilon_{i t}
$$

where

$f$ is a vector of fundamental value characteristics such as income, expenses, and lease terms $\underline{n}$ are national economic concomitants of value $\underline{r}$ are regional economic concomitants of value

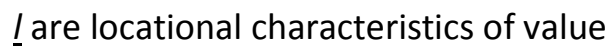


$g$ are temporal characteristics of value

$\underline{P}_{i t}$ is the price of the ith property at time $t$.

The Hoag model differs from the HPM in that financial characteristics are considered in addition to physical characteristics. Not only does the Hoag model consider the micromarket within which the property trades but also macromarket influences such as national and regional factors are introduced into real estate valuation. No macromarket orientation is incorporated into the traditional HPM. A finding of the Hoag study is that all financial characteristics considered are important industrial real estate value determinants. Regional and national factors are also found to add explanatory power. This regional finding however is based on only one significant regional variable - regional volume of industrial property sales. Hoag posits that micromarket locational attributes are responsible for dampening regional effects. No attempt is made however to test whether industrial real estate submarkets exist nor to determine the appropriateness of a micromarket pricing paradigm. ${ }^{2}$

The preceding urban land economic perspective contrasts with the asset valuation paradigms in finance. Finance valuation models focus on the return rather than the price of a property. This return is a function of one or more risk attributes rather than physical characteristics or a combination of physical and financial attributes from both a micromarket and macromarket perspective. These risk attributes arise from the covariation with return on other assets. Thus, prices are conceptually mapped into return space and the corresponding physical characteristics are mapped into the risk attribute space. Since the mapping is not one-to-one nor necessarily onto, the finance models are not substitutes for the HPM although both types of pricing paradigm are regarded as equilibrium models.

One finance model used is the capital asset pricing model (CAPM). The CAPM presumes that the domestic U.S. market is integrated; one overall market segment exists. The CAPM describes expected return on an asset as a function of its covariation with return on all other assets in the market portfolio. This covariation is known as systematic risk. Investors are only compensated for bearing this market risk in a CAPM world since non-market risk is diversifiable from a domestic perspective. The international finance literature however recognizes that some of the systematic risk is unsystematic risk from a world perspective. The international CAPM literature also recognizes the possibility that the world market is segmented with respect to national capital markets. In testing whether a segmented world capital market exists, the literature assumes a two-country investment environment. The government in one country is presumed to impose investor restrictions on total foreign investment or the type of stocks

\footnotetext{
${ }^{2}$ Research on the market segmentation issue using the Hoag paradigm is currently in process at the University of North Carolina. The working paper of Cole and Miles [1986] represents one such attempt.
} 
purchased. Investors of the other country on the other hand have no investment restrictions. Markets are defined as segmented if:

i. the restricted set of assets exhibit a premium over and above the premium for world market risk, and

ii. the unrestricted set of assets on the other hand do not exhibit a risk premium in addition to market risk.

In the extreme case of total market segmentation, separate CAPMs are assumed to hold with the asset return a function of the market return corresponding to the national market exchange in which a particular stock trades. Weak empirical evidence exists in support of a segmented international capital market (see for example Errunza and Losq [1985] and Jorion and Schwartz [1986]). No empirical CAPM evidence exists however as to whether the real estate market is segmented in terms of market risk, i.e., different risk premiums exist for properties identical in terms of market risk but located in different geographical areas. Draper and Findlay [1982] cite inadequate real estate data, lack of a suitable real estate market or submarket index and a poor fit between the real estate asset and the market within which it trades to the CAPM assumptions as reasons why no in-depth real estate study using the CAPM has thus far occurred.

A newer financial paradigm known as the arbitrage pricing model (APT) is also used to value assets. An arbitrage pricing world assumes like the CAPM that asset markets are perfectly competitive and frictionless. Further, all individuals believe that returns on assets are generated with the following linear- $k$ factor model:

(3)

$\tilde{r}_{i}=E_{i}+b_{i 1} \tilde{\delta}_{1}+b_{i 2} \tilde{\delta}_{2}+\ldots \ldots \ldots . . .+b_{i k} \tilde{\delta}_{k}+\tilde{\epsilon}_{i}$ for $i=1, \ldots, N$

where

$r_{i}$ is the return on asset $i$

$E_{i}$ is the expected return on asset $i$

$b_{i k}$ is the reaction in asset i's returns to common factor $\partial_{k}$ movements

$\delta_{k}$ is the common factor that influences the return on all assets; $E\left(\delta_{k}\right)=0$

$\epsilon_{i}$ is an unsystematic effect on asset i's return. The assumption is that this effect is diversifiable in large portfolios; $E\left(\epsilon_{i}\right)=0$

$N$ is the number of assets.

This assumption of a linear return-generating model is not required in a CAPM world. No presumption is made ex-ante in the APT that one of the factors is the "market" nor is the existence of a 
market portfolio required to derive the APT. The CAPM in contrast to the APT requires that the market portfolio exist. In equilibrium, the returns on a zero systematic risk portfolio constructed with no net investment is assumed to equal zero given that the $\epsilon_{i}$ vanish in a large portfolio. A linear algebra theorem coupled with this economic argument yields the following no arbitrage equilibrium relationship:

(4)

$$
E_{i}=\lambda_{0}+\lambda_{1} b_{i 1}+\ldots \ldots \ldots \ldots+\lambda_{k} b_{i k}
$$

where $\lambda_{0}$ is the expected return on an asset with zero systematic risk i.e., $b_{01}=b_{02}=\cdots=$ $b_{0 k}=0 ; \lambda_{0}=E_{0}$ $\lambda_{i} i=1, \ldots . ., k$ are the factor risk premia.

Mathematically, the CAPM and APT appear related with the CAPM representing a special case of the APT although different assumptions are used in the derivation of each model. This relationship according to Chen [1983, pp. 1396] will exist, "if and only if there exists a rotation of factors such that one of the factors is the 'market'. Ex ante, there is no reason to assume that this is the case ...."

Thus far, no international finance literature exists which tests whether the international capital market is segmented using an APT framework. Adler and Dumas [1983] however have suggested that the APT framework is amenable for testing the segmented capital market hypothesis. The proposed test is similar in nature to testing for real estate market segmentation in terms of the HPM since risk factors that are common to stocks of different countries are tested to determine whether the stocks receive the same risk premiums in the different national stock markets. No real estate study thus far however has examined market segmentation in real estate with respect to an APT risk-return framework. Draper and Findlay [1982] have raised a question as to whether the APT is of practical value in real estate. The point made is that not only are factors unidentifiable but also no individual property microdata or general economic data is required. Factor identification is important in tests of market segmentation since knowledge is required as to whether factor 1 in one market segment is similar or identical to factor 1 in another market segment. Without factor identification, it is difficult to test whether risk factors that are common to real estate located in different geographical areas receive the same risk premiums. Roll and Ross [1980] recognize this problem in initially testing the APT. The methodology that Roll and Ross use to get around this problem involves testing whether the intercept term varies across different groups of stock. 
In summary, evidence exists that the housing market is segmented geographically in terms of prices paid for properties having identical physical attributes. Controversy exists however as to whether a micromarket is appropriate for valuing real estate. The housing segmentation studies have employed the hedonic pricing paradigm only. No real estate segmentation study thus far has used the Hoag model, the CAPM nor the APT. Literature is also nonexistent on the related issues of industrial real estate market segmentation and the appropriateness of using an industrial submarket orientation in pricing real estate. The subsequent sections of this paper address these issues in terms of an APT framework. Factor congruency analysis is used in the present study to investigate which factors are similar or identical across market segments (c.f, Rummell 1970, pp. 461). The present study will demonstrate that the factors do capture city and regional macromarket phenomena.

\section{The Data}

This study employs quarterly real estate return data from a large, commingled real estate fund (CREF). The data has several advantages over data used in previous studies of this nature. These advantages are discussed in Hartzell, Hekman and Miles [1986].

The CREF portfolio consists of a large number of properties that are diverse with respect to property type and geographic region. The full portfolio grew in size to 382 properties with a combined market value of \$2.6 billion in September of 1983 from 113 properties with a total market value of \$129 million in September of 1973. Of the 113 properties that were in the full sample at the beginning of the sample period, 78 remained in the sample for the entire 40-quarter period. Table 1 presents a summary description for the 78 properties that are continuously held, with office buildings representing an additional $13 \%$. Retail and residential properties represent the remaining $10 \%$ of the portfolio. $\mathrm{A}$ majority of the properties are located in the Midwest although the western region ranks highest with respect to aggregate property market value.

To calculate holding period returns (HPR) for the ith property, the following formula is used:

(5)

$R_{i, t}=\left[\frac{M V_{i, t+1}+N O I_{i, t}}{M V_{i, t}+I_{i, t}}\right]-1$

where $R_{i, t}$ is the holding period return for the ith property in period $t$

$M V_{i, t+1}$ is the end of the period market value

$M V_{i, t}$ is the beginning of the period market value 
$N O I_{i, t}$ is net operating income earned in period $t$

$I_{i, t}$ is the change in cash investment (if any) which occurred in period $t$.

Problems of acquisition bias do not arise since all 78 properties are held for the entire period.

The market values used in calculation of HPR are appraisal values for each quarter of the sample period. Problems associated with using appraisals rather than actual transaction prices for empirical work are well known. An indication of the accuracy of appraisals for the full CREF portfolio is obtained through comparing actual transaction values for properties sold from the portfolio to the last appraised value. For the 89 CREF properties sold, appraisals underestimated the actual transaction price $8.7 \%$ on average. Reasons for this conservative appraisal estimate might include 1) the fact that appraisals are made a full quarter and perhaps even a full year prior to the sale date and 2) the greater incentive of the real estate fund to sell if the potential buyer bid more than the appraised price. The latter case suggests that a bias might exist supporting the conservative nature of the appraisals. Miles [1984] and Miles and McCue [1984] provide a complete discussion of commingled real estate funds and the appraisal process.

\section{TABLE 1}

\section{Property Description 78 Continuously Held Properties}

\begin{tabular}{|c|c|c|c|c|}
\hline \multicolumn{5}{|c|}{$\begin{array}{l}\text { Regional Distribution (000's) } \\
\text { As of September 30, } 1983\end{array}$} \\
\hline Region & Number & Percent & Market Value & Percent \\
\hline East & 1 & 1.28 & \$ 1,675 & 1.10 \\
\hline West & 19 & 24.35 & 67,210 & 44.18 \\
\hline Midwest & 47 & 60.25 & 49,335 & 32.43 \\
\hline South & 11 & 14.12 & 33,905 & 22.29 \\
\hline Total & 78 & 100.00 & $\$ 152,125$ & 100.00 \\
\hline \multicolumn{5}{|c|}{$\begin{array}{l}\text { Property Type Distribution (000's) } \\
\text { September } 30,1983\end{array}$} \\
\hline Region & Number & Percent & Market Value & Percent \\
\hline Industrial & 67 & 85.90 & $\$ 115,502$ & 75.93 \\
\hline Office & 6 & 7.69 & 20,170 & 13.26 \\
\hline Retail & 3 & 3.85 & 10,253 & 6.74 \\
\hline Residential & 2 & 2.56 & 6,200 & 4.08 \\
\hline Motel/Hotel & 0 & 0.00 & 0 & 0.00 \\
\hline Total & 78 & 100.00 & $\$ 152,125$ & 100.00 \\
\hline
\end{tabular}




\section{Methodology}

The methodology for testing whether industrial real estate submarkets exist basically follows from Roll and Ross [1980] with modifications made to address the market segmentation issue. Following are the steps in this methodology.

Step 1: A separate maximum likelihood factor analysis is carried out on property holding period returns for each of three geographic regions. ${ }^{3} \mathrm{~A}$ chi-squared test is used to determine the number of significant factors to retain. Only the Midwest, South, and West regions are used as market segments since only one property is located in the East region. The Midwest region is randomly divided into two groups with 23 properties in the first group known as NORTH1 and 24 properties in the other group known as NORTH2. Partitioning of the Midwest properties is done to test the validity of the APT. Ex-ante, both the NORTH1 and NORTH2 properties should exhibit not only the same number of priced factors but also the same factors that are priced if the APT holds for real estate. In addition to this, a similar $R^{2}$ should obtain for both the NORTH 1 APT and the NORTH2 APT.

Step 2: The diagonal matrix of idiosyncratic risks (the diagonal matrix of unique variances) generated as part of the factor analytic process is used as the weighting matrix in a generalized least squares (GLS) formulation to derive the average risk premia estimates $\left(\lambda_{i}\right)$ for each market segment. Following is the GLS formulation:

(6)

$$
\hat{\underline{\hat{\lambda}}}_{j}=\left(\hat{B}_{r}{ }^{\prime} D^{-1} \hat{B}_{r}\right)^{-1} \hat{B}_{r}{ }^{\prime} D^{-1} \underline{E R}_{j}
$$

where

$B_{r}$ is the varimax rotated factor loading matrix associated with the $r$ factor solution for the $j$ th market segment,

$D$ is the diagonal matrix containing the own (unique) asset variances along the principal diagonal for the jth market segment,

$E R_{L_{-}}$is the expected return vector for the ith market segment.

Ordinary least squares (OLS) is used in implementing GLS through a data transformation technique discussed in Johnston [1984, pp. 291]. ${ }^{4}$

\footnotetext{
${ }^{3}$ The use of appraised data in lieu of market prices results in slightly reduced factor loadings assuming random measurement error.

${ }^{4}$ Johnston demonstrates that OLS is useful in implementing GLS if there exists a nxn nonsingular transformation matrix $T$ such that $T_{y}=(T X) \beta+T u$ with $E($ TuuT $)=\sigma^{2} I$ and TT $=W^{-1}$. Applying OLS to $T_{y}=(T X) \beta+T u$ results in $b^{*}=\left(X^{\prime} W^{-1} X\right)^{-1} X^{\prime} W^{-1}$ with $\operatorname{var}\left(b^{*}\right)=\sigma^{2}\left(X^{\prime} W^{-1} X\right)^{-1}$ where $b^{*}$ is the GLS estimator. The procedure for obtaining the $T$-matrix is given on pages 152-153 of Johnston [1984].
} 
Step 3: A series of F-tests are constructed to investigate whether the risk premiums are equal for risk factors that are common to industrial properties located in different regions (market segments). Factor congruency analysis is used to investigate the similarity of risk factors across market segments. Congruency coefficients are computed to relate each factor of one region to each factor of another market segment. This coefficient ranges in value from +1 for perfect agreement to -1 for perfect inverse agreement (Rummel 1970, pp. 460). Mathematically, the factor congruency coefficient between factors $p$ and $q$ is

$$
c c_{p q}=\left[\frac{\sum_{j=1}^{n} b_{j p} b_{j q}}{\left[\left(\sum_{j=1}^{n} b_{j p}^{2}\right)\left(\sum_{j=1}^{n} b_{j q}^{2}\right)\right]^{1 / 2}}\right]
$$

where $b_{j}$ represents the factor scores (factor loadings) of the two factors $p$ and $q$. Standardized factor scores are used in the present study in lieu of factor loadings since the number of time periods are identical for all properties; the number of properties in each region differ. Harmon $(1976$, pp. 344) notes that the coefficient is not a correlation coefficient if the factor loadings are used. However, one can mathematically demonstrate that the factor congruency coefficient is equivalent to a correlation coefficient if standardized factor scores are used since the mean of each factor score is zero, i.e., $E\left(b_{j p}\right)=E\left(b_{j q}\right)=0$. The present study considers a pair of factors similar if the correlation coefficient between standardized factor scores is statistically significant at the $99 \%$ confidence level. Cavusgil [1984] has used the factor congruency method to compare national factors in an export study involving the U.S., Great Britain, and Norway.

Step 4: An attempt is made to identify the priced factors for each region (market segment) using physical and financial characteristics associated with each property. The variables considered include age, average lease maturity, region of the country, the total amount of square feet, number of tenants and the availability of rail service. Studies such as Blackley [1984, 1985], Hartnett [1973], Hoag [1980], Lee [1982], Nelson, Pollankowski and Sabrosky [1980] and Schmenner [1981] have found these characteristics significant in accounting for price variation in industrial real estate. Correlation coefficients are computed between the factor scores for all priced factors in each region and the expected inflation rate, the unexpected inflation rate, the quarterly risk-free rate for 3-month T-bills and a return index comprised of all equity REITs to determine whether priced factors represent general economic phenomena. This procedure is necessary since none of the physical nor financial 
characteristics considered reflect general economic phenomena. Hartzell, Hekman and Miles [1986] for example find that inflation impacts significantly on real estate portfolios. The data for these variables are taken from their study.

Step 5: The seemingly unrelated regressions (SUR) methodology of Zellner [1962] is used as an alternative parameter estimation technique to investigate whether the contemporaneous correlation among disturbances from the regional pricing models imparts any additional information on the parameter estimates. SUR methodology allows for the interrelationship among regional pricing models through the disturbance terms. The contemporaneous correlations among disturbances if different equations thus reveal any interregional relationships. Through application of the SUR estimation technique, joint influences are reflected in parameter estimates. A likelihood ratio test is carried out to determine whether the resulting parameter estimates arising from a joint GLS methodology are more efficient relative to parameter estimates from separate APT regression equations (cf., Judge, et al. [1985, pp. 472-477].

The Chen [1983] methodology is employed to investigate the appropriateness of a national, integrated real estate market orientation in pricing industrial properties. This procedure is necessary since there are only 40 quarters of holding period returns for 78 properties which results in a singular variance-covariance matrix. Factor loadings arising from factor analyzing a singular variance-covariance matrix are therefore not "meaningful". Following is an outline of the estimation procedure:

i. A sample covariance matrix is computed from the holding period returns of 30 properties chosen using a stratified random sample. The proportion of properties located in each region is used as the basis for stratification.

ii. The first 10 -factor loadings for each property is obtained with the computer software package SAS.

iii. Five portfolios (10 portfolios) are formed using the Lehmann-Modest [1985a, 1985b] nonlinear programming methodology in lieu of the linear programming portfolio formation technique of Chen given the proprietary nature of the Chen software. Mathematically, the portfolio weights are chosen such that:

(8) $\min \underline{x}_{j}{ }^{\prime} D \underline{x}_{j}\left\{\underline{X}_{j}\right\}$ subject to $\underline{x}_{j}{ }^{\prime} \underline{b}_{k}=0$ for all $j=k \underline{x}_{j}{ }^{\prime} \underline{i}=1$ 
where $i$ is the vector of ones. ${ }^{5}$ The resulting portfolios are minimum idiosyncratic risk portfolios whose return variations are proportional to the ith common factor.

iv. The first 5-(10) factor loadings are computed for each industrial property using equation (Al) in Chen [1983, pp. 141].

v. The APT model for the entire sample of 78 properties is alternatively estimated with 5 and 10 factors.

\section{Analysis of Results}

Evidence exists that the industrial real estate market is segmented on a regional basis. The number of priced factors vary for each region given separate regional APTs. Only one factor is priced for either group of properties located in the northern region at the $5 \%$ level of significance. Four out of five factors on the other hand are priced in the South while significant risk premiums exist for three out of six western factors. The intercept term is significant for the APT models associated with both sets of northern properties ( $5 \%$ level) and properties located in the West (10\% level). However, an insignificant intercept term is present for the south APT model. All of the regional models account for a major portion of the return fluctuations for industrial properties located in that region. The northern APT models account for $54-66 \%$ of the variation in property returns. A lower proportion (45\%) of the return fluctuations is accounted for in the western region even though more factors are priced for the western region relative to either set of northern properties. The APT model for southern properties on the other hand accounts for almost $80 \%$ of the variations in holding period return. Separate APT models for each region are shown in Table 2 with T-statistics in parentheses.

Most of the factors for a particular region are not related to factors in any other region. An exception to this are the factors associated with the NORTH1 and NORTH2 group of properties which is not unexpected. Table 3 depicts all significant interregional factors. None of the intraregional factors are significantly correlated. This finding is expected since an orthogonal (varimax) rotation is used in the factor analysis process. The first factor of the first group of northern properties (F1N1) is similar to the first factor associated with NORTH2 properties (F1N1). Only this first factor is priced in either northern APT model. Further, the risk premium for $F 1 N 1$ is not significantly different from the risk premium for F1N2 (see Table 4). Thus, the "market" within which the first group of northern properties trade is integrated with the "market" for the second group of northern properties. Both F1N1 and F1N2 are

\footnotetext{
${ }^{5}$ The nonlinear program known as GINO developed by Leon Lasdon at the University of Texas-Austin is used to generate the portfolio weights. The authors thank Leon Lasdon for making this software available to us.
} 
correlated with the third factor in the western region (F3W). The factor $F 3 W$ however is not priced in the western APT model in contrast to F1N1 and F1N2 which are priced. F-tests reveal that the risk premium for F3W also differs significantly from the risk premiums associated with F1N1 and F1N2. Other factors that are correlated between the two groups of northern properties include F2N1 with F1N2 and F3N1 with F2N2. No evidence exists that the risk premiums for the respective relationship are statistically different. Both F3N1 and F2N2 are also related to the fifth factor in the western region (F3N1). The risk premium for $F 5 W$ does not significantly vary from either the $F 3 N 1$ risk premium or the F2N2 risk premium. None of these factors however are priced in their respective APT models. A slight relationship also exists between F4iVI and F3N2. The fifth factor is either group of northern properties however does not appear related to any other northern factor. A possible explanation is that the first four factors in either northern property group capture most of the systematic variation in property returns. A significant factor similarity exists when the first factor in the western region (F1W) is compared to the third factor in the southern region (F3S). Both factors are priced in their respective regional APT model although the risk premium for F3S is significantly greater than that for F1W. All of the regional APT models have cross-sectional explanatory power since the null hypothesis $\lambda_{1}=\lambda_{2}=$ $\cdots=\lambda_{k}=0$ for each region is not accepted (see the last four hypotheses test in Table 4).

\section{TABLE 2}

\section{Cross-Sectional GLS Regression of Mean Sample Returns on Factor Loadings for Each Region}

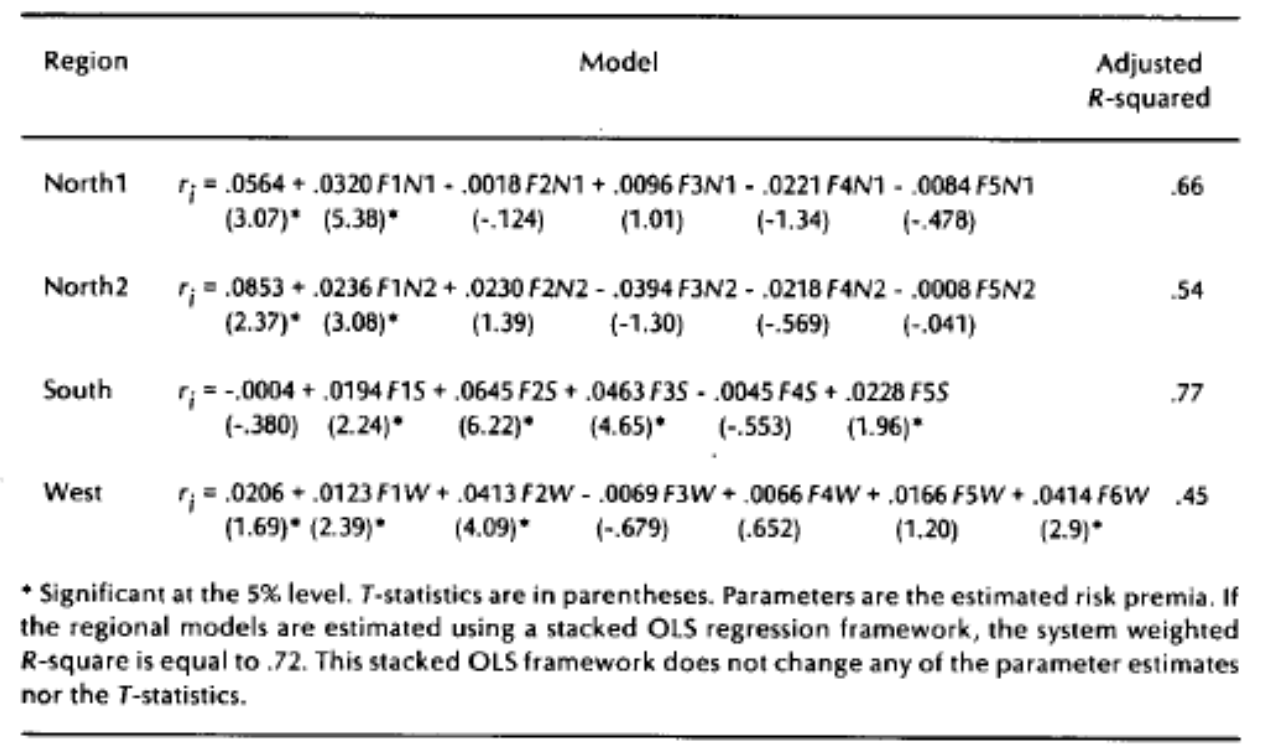


TABLE 3

\section{Factor Congruency Analysis: Test for Similar Interregional Risk Factors}

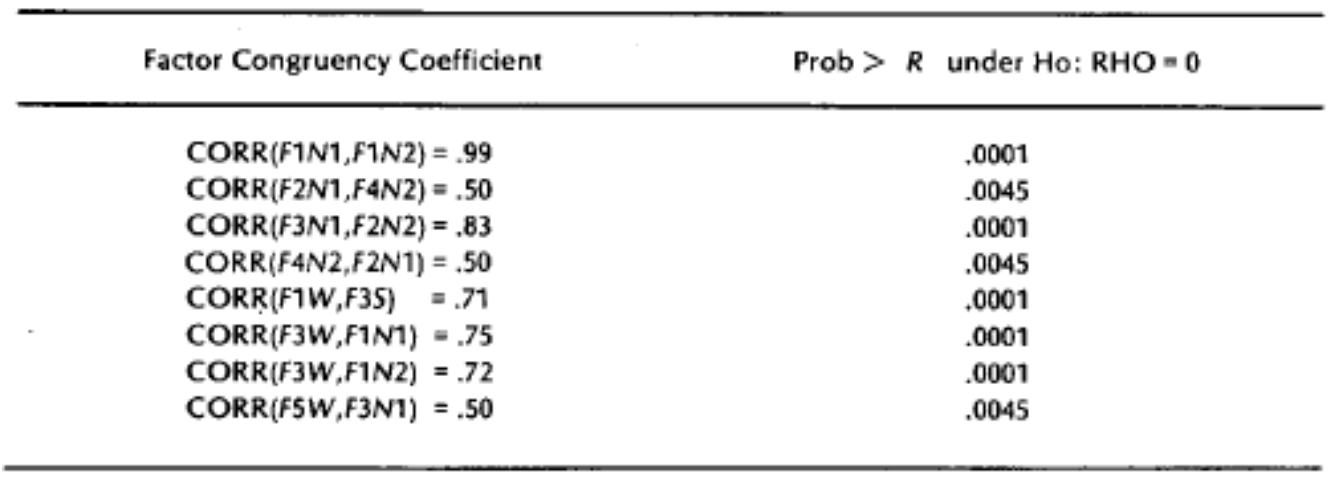

TABLE 4

F-Tests for the Equality of Cross-Regional Risk Premia

\begin{tabular}{lll}
\hline Hypothesis Tested & Computed $F$-Value & Prob $>F$ \\
\hline & & \\
$\lambda_{F 1 N 1}=\lambda_{F 3 W}$ & $F(1,71)=10.86$ & $.0015^{*}$ \\
$\lambda_{F 1 N 1}=\lambda_{F 1 N 2}$ & $F(1,71)=.7626$. & .3855 \\
$\lambda_{F 1 N 2}=\lambda_{F 3 W}$ & $F(1,71)=5.722$ & $.0194^{*}$ \\
$\lambda_{F 2 N 1}=\lambda_{F 4 N 2}$ & $F(1,71)=.2336$ & .6303 \\
$\lambda_{F 3 N 1}=\lambda_{F 5 W}$ & $F(1,71)=.1723$ & .6793 \\
$\lambda_{F 3 N 1}=\lambda_{F 2 N 2}$ & $F(1,71)=.4934$ & $.4847^{\prime}$ \\
$\lambda_{F 2 N 2}=\lambda_{F 5 W}$ & $F(1,71)=.0883$ & .7672 \\
$\lambda_{F 1 W}=\lambda_{F 3 S}$ & $F(1,71)=9.251$ & $.0033^{*}$ \\
$\alpha_{N 1}=\alpha_{N 2}=\alpha S=\alpha_{W}$ & $F(3,71)=6.024$ & $.0011^{*}$ \\
$\lambda_{F 1 N 1}=\lambda_{F 2 N 1}=\lambda_{F 3 N 1}=\lambda_{F 4 N 1}=\lambda_{F 5 N 1}=0$ & $F(4,71)=6.007$ & $.0003^{*}$ \\
$\lambda_{F 1 N 2}=\lambda_{F 2 N 2}=\lambda_{F 3 N 2}=\lambda_{F 4 N 2}=\lambda_{F 5 N 2}=0$ & $F(4,71)=3.766$ & $.0078^{*}$ \\
$\lambda_{F 1 W}=\lambda_{F 2 W}=\lambda_{F 3 W}=\lambda_{F 4 W}=\lambda_{F 5 W} \lambda_{F 6 W}=0$ & $F(5,71)=2.932$ & $.0183^{*}$ \\
$\lambda_{F 15}=\lambda_{F 2 S}=\lambda_{F 3 S}=\lambda_{F 4 S}=\lambda_{F 55}=0$ & $F(4,71)=10.348$ & $.0001^{*}$ \\
\hline
\end{tabular}

Legend: $\alpha$ is the intercept term of the appropriate regional APT model

$\lambda$ is the risk premium

- F-statistic is significant at the $99 \%$ confidence level; do not accept the hypothesis.

The priced factors appear to represent the major cities within each region. A summary of the average characteristics associated with all priced factors follows in Table 5. The representative property associated with either F1N1 or F1N2 is an industrial warehouse located in Chicago. The industrial warehouse is approximately 17 years old and consists of 40,000 square feet with a lease maturity of 2730 months. Only a single tenant occupies this property and there is no rail service available. Western factors F1W, F2W, and F6W represent the cities of San Francisco, Los Angeles, and Denver respectively. 
Properties associated with the first factor are primarily industrial offices housing more than one tenant per building. The average industrial office is 15 years old and has approximately 52,500 square feet. On the other hand, the $F 2 W$ representative property is an industrial warehouse with no rail facilities available. The Los Angeles property is at least three times the size of the San Francisco property averaging 185,000 square feet. While the age of the property is similar to those in $\mathrm{F} 1 \mathrm{~W}$, the average lease maturity for $\mathrm{F} 2 \mathrm{~W}$ is four times longer (74 months) than $\mathrm{F} 1 \mathrm{~W}$ properties. Denver properties are also primarily industrial offices approximately 14 years old with more than one tenant occupying each property. These Denver properties average 60,000 square feet and are therefore smaller than Los Angeles industrial offices. Southern factors also reflect the major cities within which southern industrial real estate is traded. Atlanta, Dallas, Houston, and a combination of Atlanta-Dallas are the southern cities that factors F1S, F2S, F3S and F5S capture respectively. Atlanta properties are multi-tenant offices located in the suburbs. Each office building averages 95,000 square feet with 25 months remaining on the lease in general. Properties located in Dallas and Houston in contrast have 14-16 months remaining on the lease. The real estate is typically smaller than factor $F 1 S$ with Dallas properties averaging 50,000 square feet and Houston properties generally containing 65,000 square feet. Both Atlanta and Houston properties associated with F1S and F2S respectively are 17 years old on average. Dallas properties on the other hand are typically three years newer. The last southern factor is a combination of two cities with property age and the number of tenants as the distinguishing characteristics.

\section{TABLE 5}

\section{Summary Characteristics of Priced Factors}

\begin{tabular}{llrlllc}
\hline Factor & \multicolumn{1}{c}{ City } & $\begin{array}{c}\text { Square } \\
\text { Feet }\end{array}$ & Age & $\begin{array}{c}\text { Property } \\
\text { Type }\end{array}$ & $\begin{array}{c}\text { Avg. Lease } \\
\text { Maturity }\end{array}$ & $\begin{array}{c}\text { Number of } \\
\text { Tenants }\end{array}$ \\
\hline F1N1 & Chicago & 37,000 & 17 & IW-Nonrail & 30 & 1 \\
F1N2 & Chicago & 41,000 & 17 & IW-Nonrail & 27 & 1 \\
F1W & San Francisco & 52,500 & 15 & IO & 17 & 1 \\
F2W & Los Angeles & 185,000 & 14 & IW-Nonrail & 75 & More Than 1 \\
F6W & Denver & 61,500 & 14 & IO & 41 & More Than 1 \\
F1S & Atlanta & 95,000 & 17 & Office-Sub & 25 & More Than 1 \\
F2S & Dallas & 50,000 & 14 & IW-Both & 14 & Varies \\
F3S & Houston & 65,000 & 17 & IO & 16 & More Than 1 \\
F5S & Atlanta-Dallas & Varies & 13 & Varies & Varies & 1 \\
\hline
\end{tabular}

Legend: $I W=$ Industrial Warehouse, $10=$ Industrial Office, Office-Sub = Suburban Office Building Average lease maturity is a time-weighted monthly average. 
Only two priced factors associated with any region appear moderately related to general economic factors. Both factors are dimensions of returns to southern industrial real estate. Factor F2S captures a portion of expected inflation while a portion of unanticipated inflation is embedded in the fifth southern factor (F5S). The remaining priced factors exhibit relatively low correlations with general economic conditions. Correlations are shown in Table 6. This evidence contrasts with the findings of Brueggeman, et al. [1984] and Hartzell, et al. [1986]. One possible explanation for this inconsistency is that the present study analyzes only industrial real estate in contrast to more diversified property types examined in both of the previous studies. No evidence is found that general economic factors might also indirectly influence industrial real estate returns through the contemporaneous disturbances. First, the likelihood ratio test comparing the covariance matrix of disturbances from SUR with the stacked OLS covariance matrix of disturbances indicates that no additional information is incorporated in parameter estimates. Secondly, the E-squared associated with the SUR simultaneous equation framework (.75) accounts for only $3 \%$ more of the variation in industrial real estate returns relative to a stacked OLS framework (with .72 i2-squared). No strong interregional relationship is thus present among regional pricing models. Table 7 depicts both the SUR parameter estimates and the likelihood ratio results.

\section{TABLE 6}

\section{Correlation Coefficients between Priced Factors and General Economic Factors}

\begin{tabular}{|c|c|c|c|c|c|c|c|c|c|}
\hline \multirow{2}{*}{$\begin{array}{l}\text { Economic } \\
\text { Factors }\end{array}$} & \multicolumn{6}{|c|}{ Priced Factors } & \multicolumn{3}{|l|}{$\cdot$} \\
\hline & F1N1 & F1N2 & F1W & $F 2 W$ & F6W & F1S & F2S & F3S & F5S \\
\hline $\begin{array}{l}\text { Expected } \\
\text { Inflation }\end{array}$ & .14 & .12 & .15 & .21 & -.15 & .19 & .54 & .12 & -.20 \\
\hline $\begin{array}{l}\text { Unanticipated } \\
\text { Inflation }\end{array}$ & .20 & .01 & -.05 & -.17 & .23 & -.21 & -.22 & .06 & .44 \\
\hline $\begin{array}{l}\text { Quarterly Risk-free } \\
\text { Rate of Return }\end{array}$ & -.02 & -.03 & .29 & .30 & -.17 & .34 & .14 & .02 & -18 \\
\hline $\begin{array}{l}\text { Return on Equity } \\
\text { REITs }\end{array}$ & .20 & .23 & -.15 & .06 & -.08 & -.26 & .17 & -.31 & -.08 \\
\hline
\end{tabular}

Given the low level of interregional relationships, it is not surprising to find that a regional orientation is more appropriate in pricing industrial propeties compared to a national perspective. The 5 -factor and 10 -factor national APT models account for only $31 \%$ and $39 \%$ of the return variation in all properties respectively. This contrasts with the $.45-.77$ adjusted $R$-squareds for the regional pricing 
models. A visual inspection of the residuals confirms that the regional APT models better predict returns. Table 8 displays the APT results for a 5 -factor and a 10 -factor model respectively assuming that an integrated, national industrial real estate market exists. Two factors $\{F 2$ and $F 4$ ) are priced in the 5factor APT model while two additional risk premiums are significant (F6 and F8) in the 10-factor APT model. Both the intercept term for the 5 and 10-factor models are also significant. All of the priced factors for the national APT models reflect either a city or regional influence. This regional dimension is not present in the regional APT models, i.e., properties located in different cities within a given region do not typically load highly on the same factor. Factor 2 represents industrial properties located in either Denver or Dallas built between 1971 and 1973. These properties have an average area of approximately 75,000 square feet. Factor 4 on the other hand consists of Far West industrial properties. San Francisco, Los Angeles, and Seattle are the major cities loading highly on this factor. The properties have no distinguishing characteristics in common. The city of Houston and St. Louis represent factor 6 and factor 8 respectively. All of the Houston properties are industrial offices built in 1971. More than one tenant occupies each building. No common attributes are identifiable for properties located in St. Louis. Surprisingly, none of the Chicago factors are priced even though $60 \%$ of the industrial real estate evaluated is located in the Midwest region. Both factor 3 and factor 5 represent Chicago properties with the former factor consisting of pre-1970 buildings while post-1970 industrial properties are included in the latter factor. A possible explanation for this phenomenon is that the variability in industrial real estate returns is greater in the West and South compared to the Midwest region. 
TABLE 7

\section{Cross-Sectional Seemingly Unrelated Regression Mean Sample Returns on Factor Loadings}

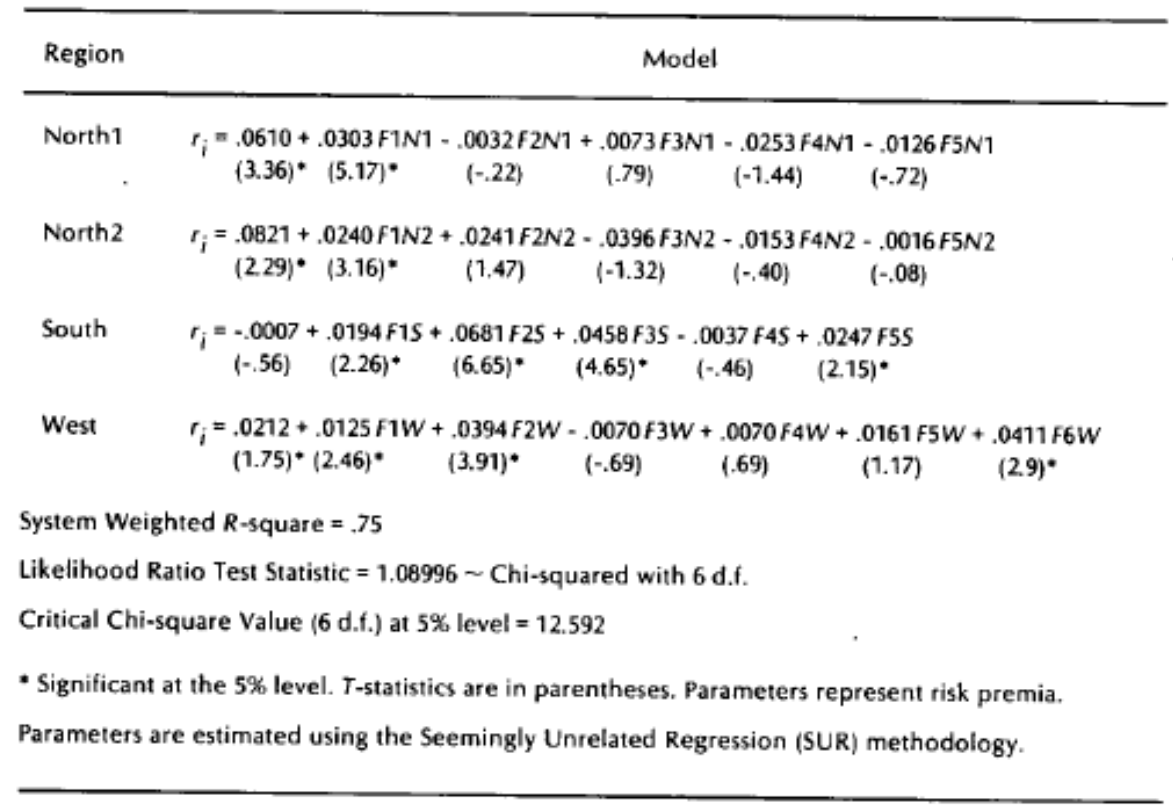

TABLE 8

Five-Factor and Ten-Factor APT Models (Assuming that a National Industrial Real Estate Market Exists)

\begin{tabular}{ccccc}
\hline Variable & $\begin{array}{c}\text { Parameter Estimates } \\
\text { for 5-Factor Model }\end{array}$ & $\begin{array}{c}T- \\
\text { Values }\end{array}$ & $\begin{array}{c}\text { Parameter Estimates } \\
\text { for 10-Factor Model }\end{array}$ & $\begin{array}{c}T- \\
\text { Values }\end{array}$ \\
\hline Intercept & .0247 & $13.87^{*}$ & .0247 & $12.15^{*}$ \\
F1 & .0056 & .75 & .0106 & 1.48 \\
F2 & .0187 & $4.02^{*}$ & .0175 & $3.7^{*}$ \\
F3 & .0025 & .51 & -.0072 & -1.29 \\
F4 & .0199 & $5.39^{*}$ & .0188 & $5.05^{*}$ \\
F5 & .0007 & .24 & .0032 & 1.05 \\
F6 & & & .0179 & $-.88^{*}$ \\
F7 & & & -.0049 & -.72 \\
F8 & & & -.0122 & $1.99^{*}$ \\
F9 & & & -.0079 & -1.44 \\
F10 & .3099 & & -.0038 & -.51 \\
Adj. R-squared & & & .3962 & \\
\hline
\end{tabular}

- Risk premium is significant at the $5 \%$ level.

\section{Summary and Conclusions}

The empirical evidence in this study supports the existence of regional markets for industrial real estate. Not only does the risk premium(s) associated with a common systematic risk attribute(s) vary for properties located in different regions but also the number of priced risk factors differs across 
regions. Some risk factors are systematic across two or more regions while other risk factors are systematic only within a given region (and consequently unsystematic from a national as opposed to regional orientation). Further, some of the risk factors priced are unique to a given region while ubiquitous risk factors are not compensated for in all regions. Thus, different risk attributes influence property return in each regional market. The priced factors represent major cities within each region rather than general regional factors. No evidence is found to support the notion that general economic factors are embedded in the risk attributes. This suggests that constructing city real estate indices according to property type might prove a fruitful endeavor. A possible explanation for this phenomenon is that each city within a given region has a unique economic base.

A submarket orientation rather than an "integrated" perspective is found more appropriate in predicting returns on industrial real estate. Both the 5 and 10-factor APT models that assume a national or integrated industrial real estate market account for less than $40 \%$ of the variation in returns. All regional APT models in contrast exhibit between a $.45-.77$ adjusted $R$-square. A visual inspection of residuals also indicates that better predictions arise from the regional APT models.

\section{References}

M. Adler and B. Dumas. International Portfolio Choice and Corporation Finance: A Synthesis. Journal of Finance 38(3): 925-984, 1983.

V. Bajic. Housing Market Segmentation and Demand for Housing Attributes: Some Empirical Findings. AREUEA Journal 13(1): 58-75, 1985.

P. Blackley. A Hedonic Approach to the Decentralization of Manufacturing Activity. Journal of Regional Science 24(4): 541-557, 1984.

. The Demand for Industrial Sites in a Metropolitan Area: Theory, Empirical Evidence and Policy Implications. Journal of Urban Economics 17:247-261, 1985.

W. B. Brueggeman, A. H. Chen and T. G. Thibodeau. Real Estate Investment Funds: Performance and Portfolio Considerations. AREUEA Journal 12(3): 333-354, 1984.

S. T. Cavusgil. Factor Congruency Analysis: A Methodology for Cross Cultural Research. Journal of the Market Research Society 27(2): 147-155, 1985.

N.-F. Chen. Some Empirical Tests of the Theory of Arbitrage Pricing. Journal of Finance 38(5): 1393-1414, December 1983.

R. Cole and M. Miles. Market Returns on Commercial Real Estate: Implications for Investment Analysis. Working Paper, University of North Carolina, 1986. 
D. Dale-Johnson. An Alternative Approach to Housing Market Segmentation Using Hedonic Price Data. Journal of Urban Economics 11:311-322, 1982.

D. W. Draper and M. C. Findlay. Capital Asset Pricing and Real Estate Valuation. AREUEA Journal 10(2): 152-183, Summer 1982.

V. Errunza and E. Losq. International Asset Pricing under Mild Segmentation: Theory and Test. Journal of Finance 40(1): 105-124, 1985.

A. C. Goodman. Housing Submarkets Within Urban Areas: Definitions and Evidence. Journal of Regional Science 21(2): 175-185, 1981.

H. H. Harman. Modem Factor Analysis, 3rd edition. University of Chicago Press 1976.

H. D. Hartnett. A Locational Analysis of Manufacturing Plants within the City of Chicago: 1959-1968. AREUEA Journal 1(1): 31-47, 1973.

D. J. Hartzell, J. Hekman and M. E. Miles. Diversification Categories in Investment Real Estate. AREUEA Journal 14(2): Summer 1986.

J. W. Hoag. Towards Indices of Real Estate Value and Return. Journal of Finance 35(2): 569-580, May 1980.

J. Johnston. Econometric Methods. 3rd edition. McGraw-Hill, 1984g.

P. Jorion and E. Schwartz. Integration vs. Segmentation in the Canadian Stock Market. Journal of Finance 41(3): 603-616, 1986.

G. G. Judge, W. E. Griffiths, R. C. Hill, H. Lutkepohl and T.-C. Lee. The Theory and Practice of Econometrics, 2nd edition. John Wiley and Sons, 1985.

K. S. Lee. A Model of Intraurban Employment Location: An Application to Bogota, Colombia. Journal of Urban Economics 12: 263-279, 1982.

B. N. Lehmann and D. M. Modest. The Empirical Foundations of the Arbitrage Pricing Theory I: The Empirical Tests. NBER Working Paper No. 1725, 1985.

. The Empirical Foundations of the Arbitrage Pricing Theory II: The Optimal Construction of Basis Portfolios. NBER Working Paper No. 1726, 1985.

G. S. Maddala. Econometrics. McGraw-Hill, 1977.

K. V. Mardia, J. T. Kent and J. M. Bibby. Multivariate Analysis. Academic Press, 1979.

M. Miles. Commercial Appraisals for Institutional Clients. Appraisal Journal 52(4): 550-564, 1984.

M. Miles and T. McCue. Historic Returns and Institutional Real Estate Portfolios. AREUEA Journal 10(2): 184-198, Summer 1982. 
R. D. Nelson, A. J. Pollankowski and L. Sabrosky. Appraisal of an Industrial Warehouse Property. The Real Estate Appraiser 36(2): 41-50, 1970.

M. Reinganum. The Arbitrage Pricing Theory: Some Empirical Results. Journal of Finance 36(2): 313-321, May 1981.

D. H. Richardson and R. Thalheimer. On the Use of Grouping Methods in the Analysis of Residential Housing Market. Regional Science and Urban Economics 12:285-304, 1982.

R. Roll and S. A. Ross. An Empirical Investigation of the Arbitrage Pricing Theory. Journal of Finance 35(5): 1073-1103, December 1980.

R. J. Rummel. Applied Factor Analysis. Northwestern University Press, 1970.

A. B. Schnare and R. J. Struyk. Segmentation in Urban Housing Markets. Journal of Urban Economics 3(2): 146-166, 1976.

R. W. Schmenner. The Rent Gradient for Manufacturing. Journal of Urban Economics 9: 90-96, 1981.

J. C. Sonstalie and P. R. Portney. Gross Rents and Market Values: Testing the Implications of Tiebout's Hypothesis. Journal of Urban Economics 7(1): 102-118, 1980.

M. Straszheim. Hedonic Estimation of Housing Prices: A Further Comment. Review of Economics and Statistics 56(3): 404-406, 1974.

S. Titman and A. Warga. Risk and the Performance of Real Estate Investment Trusts: A Multiple Index Approach. AREUEA Journal 14(3): 414-431, Fall 1986.

A. Zellner. An Efficient Method of Estimating Seemingly Unrelated Regressions and Tests for Aggregation Bias. Journal of the American Statistical Association 57:348-368, 1962. 